\title{
Self-Compacting Concrete with Recycled Concrete Aggregate: Resistance against Aggressive External Agents
}

\author{
Víctor Revilla-Cuesta ${ }^{1}$, Marta Skaf ${ }^{2}$, Aratz García-Llona ${ }^{3}$, Ignacio Piñero ${ }^{3}$, Juan M. \\ Manso $^{1}$ and Vanesa Ortega-López ${ }^{1}$
}

${ }^{1}$ Department of Civil Engineering, Higher Polytechnic School, University of Burgos, Villadiego St, 09001 Burgos, Spain, \{vrevilla, jmmanso, vortega\}@ubu.es. Víctor Revilla-Cuesta: Corresponding author

${ }^{2}$ Department of Construction, Higher Polytechnic School, University of Burgos, Villadiego St, 09001 Burgos, Spain, \{mskaf\}@ubu.es

${ }^{3}$ Fundación TECNALIA Research \& Innovation. Parque Tecnológico de Bizkaia. C/Geldo, ed.700, E48160 Derio-Bizkaia, Spain, \{aratz.garcia, ignacio.pinero\}@tecnalia.com

\begin{abstract}
The use of waste in civil-engineering products, such as concrete and asphalt mixes, is a very effective strategy for reducing high consumption levels of Natural Aggregates (NA) in the construction sector. In this research, rejected precast concrete elements of high compressive strength are studied, following their crushing for use as a high quality Recycled Concrete Aggregate (RCA) in the manufacture of Self-Compacting Concrete (SCC). High volumes of this waste stream are employed in the mixture, completely replacing the coarse fraction of the natural aggregate (100\% replacement rate) and half of the fine fraction (50\% replacement rate). Once hardened, samples of the recycled SCC are exposed to several aggressive external agents, in order to evaluate their performance and durability in aggressive environments. Behavioral tests on the concrete in the presence of the most frequent aggressive agents in the surrounding environment demonstrated that the SCC containing RCA was resistant to freeze/thaw and moist/dry cycles, and sulphate attack, according to the results obtained in 4, 3 and 2 samples respectively, and of sufficient durability for use in structural concrete components.
\end{abstract}

Keywords: Self-Compacting Concrete, Recycled Concrete Aggregate, Freeze/Thaw Test, Moist/Dry Test, Sulphate Attack Test.

\section{Introduction}

Modern-day society currently faces two immense environmental problems: climate change and the lack of natural resources (IPCC, 2014). Climate change is mainly due to the emission of greenhouse gases, resulting from a wide range of collective human actions related to manufacturing, transport, and energy production. High consumption in some areas of natural resources has led to shortages over recent years, as expanding populations need continual development of technology and infrastructure.

The construction sector is a major contributor to these problems (Sandanayake et al., 2019): the cement industry emits high volumes of $\mathrm{CO}_{2}$ (Maddalena et al., 2018) and many other construction activities have a high carbon footprint (Noh et al., 2018). Aggregate consumption in asphalt mixes, and concretes is also very high, in the order of $80 \%$ and $95 \%$ by volume. (CESCE, 2018). According to the Asociación Nacional de Empresarios Fabricantes de Áridos (ANEFA) [National Association of Aggregate Manufacturers of Spain], in 2017, 112 million tons of aggregates were consumed in Spain (ANEFA, 2018). The sector therefore has some responsibility to contribute to the reduction of these problems. 
Aggregate substitution in several materials, including concrete, by different types of waste, such as rubber, slag, and even Recycled Concrete Aggregate (RCA), is an area of study that has opened several research lines (Busic et al., 2018; Safiuddin et al., 2013; Verian et al., 2018). Hence, the use of RCA in this study is evaluated for the manufacture of concrete.

The mechanical performance of vibrated concrete with RCA is well-known: RCA, especially the fine fraction, decreases compressive strength (Evangelista et al., 2014; Silva et al., 2015). Durability is also affected, because of the high porosity of the attached mortar, which raises permeability levels and the entry of external agents (Guo et al., 2018).

Self-Compacting Concrete (SCC) is of greater fluidity, so its porosity is lower. RCA can even improve its durability and enhance some other properties (Boudali et al., 2016; PereiraDe-Oliveira et al., 2014). The RCA effect on mechanical properties will not change due to selfcompactability (Fiol et al., 2018; Grdic et al., 2010). Nevertheless, there is a scarcity of studies on precise definitions of the RCA effect.

In line with the above, the durability of an SCC design consisting of $100 \%$ coarse RCA and $50 \%$ by volume of fine RCA will be evaluated in this research. This concrete underwent three tests: behavior during freeze/thaw and moist/dry cycles, and resistance to sulphate attack, demonstrating its performance when exposed to highly aggressive environmental agents.

\section{Materials}

Three types of materials were employed: RCA, natural aggregates (NA), and non-aggregate.

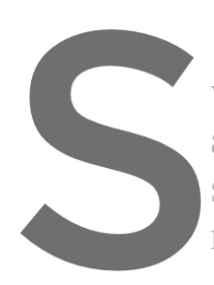

CEM I 52.5 R with a density of $3.1 \mathrm{~kg} / \mathrm{dm}^{3}$ was employed as

was obtained from the mains water supply sys
a viscosity adjuster (called admixture 1 ) and a
studies showed that, f the amount of water is
range between $0.5-1.5 \%$ of the cement weight
Only the fine NA ractions were used. Siliceor

Only the fine NA fractions were used. Siliceous sand with a density of $2.58 \mathrm{~kg} / \mathrm{dm}^{3}$ and a

$24 \mathrm{~h}$ water absorption of $0.25 \%$ was used. In addition, SCC requires a large. fines content for

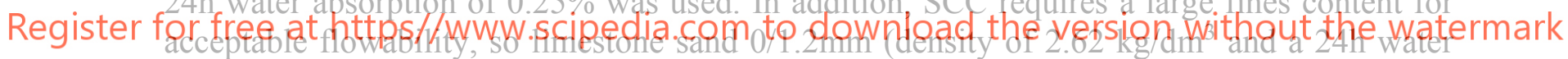

absorption of $2.08 \%$ ) and limestone filler $<0.063 \mathrm{~mm}$ (density of $2.77 \mathrm{~kg} / \mathrm{dm}^{3}$ ) were used.

The RCA consisted of rejected precast elements with a characteristic compressive strength of 40-45 MPa prior to crushing. The crushed RCA was sized between 0 and $30 \mathrm{~mm}$, for which reason it was screened to obtain the desired fractions: the fine fraction $0 / 4 \mathrm{~mm}$ (density of 2.37 $\mathrm{kg} / \mathrm{dm}^{3}$ and $24 \mathrm{~h}$ water absorption of $7.36 \%$ ) and the coarse fraction $4 / 12.5 \mathrm{~mm}$ (density of 2.42 $\mathrm{kg} / \mathrm{dm}^{3}$ and $24 \mathrm{~h}$ water absorption of $6.25 \%$ ). Particles larger than $12.5 \mathrm{~mm}$ were discarded, because they were considered too large to make an SCC.

The appearance of the aggregate and their granulometry are shown in Figure 1 and Figure 2.
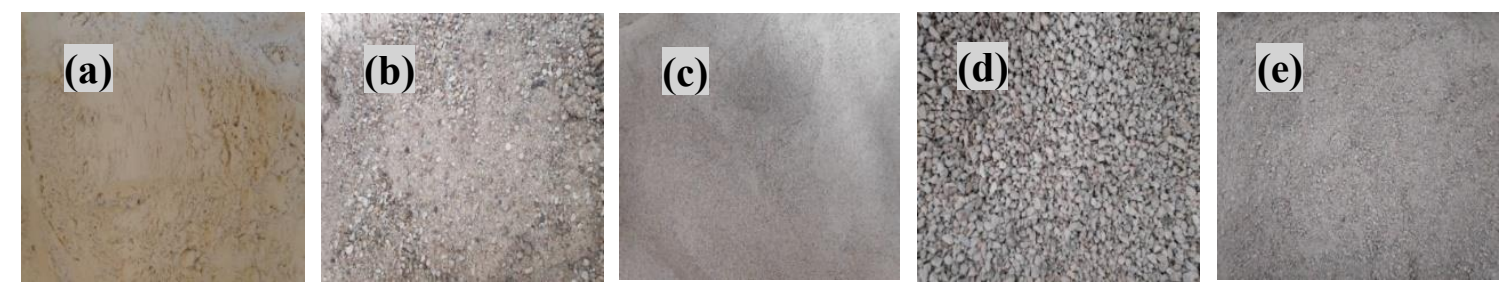

Figure 1. Appearance of the aggregates used for the manufacture of the SCC: a) Limestone filler $<0.063 \mathrm{~mm}$; b) Siliceous sand 0/4 mm; c) Limestone sand 0/1.2 mm; d) Coarse RCA 4/12.5 mm; e) Fine RCA 0/4 mm. 


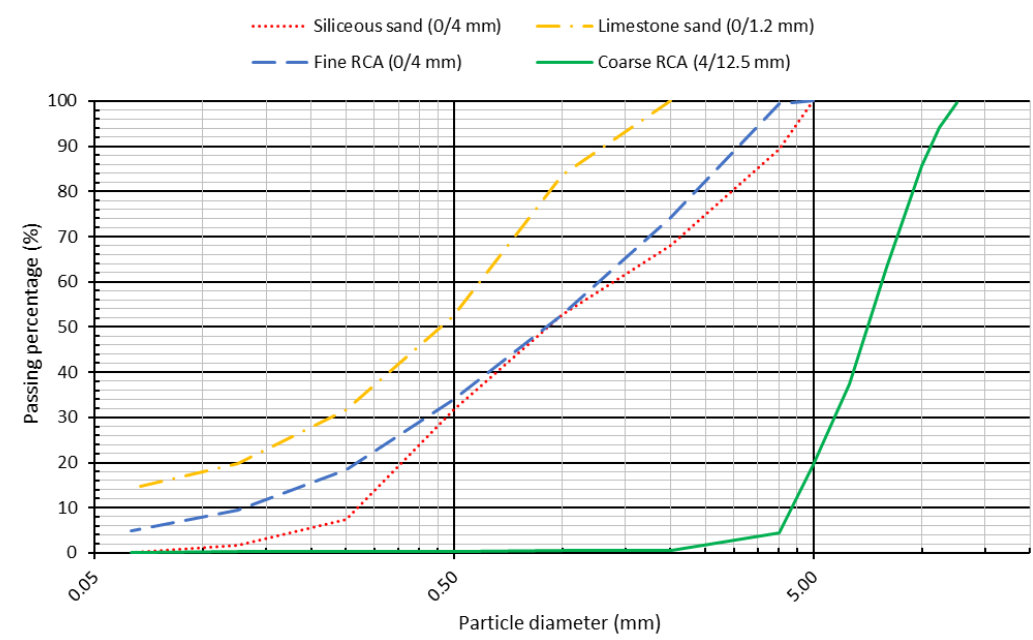

Figure 2. Aggregate granulometry.

\section{Mix-Design}

The SCC under evaluation was designed with the materials detailed in the preceding section and labelled SCC-I-50/100-D.

The dosage of the SCC was designed, so that neither segregation nor exudation would affect the final SCC and so that it would have an SF2 slump-flow class (maximum dianeter between 650 and $750 \mathrm{~mm}$ ). Design by trial and enror began with a very common dosage in cement component indu 12350-8 (EN-Euronoim stage. The process of ria the definitive optimal dosage was obtained: $296 \mathrm{~kg}$

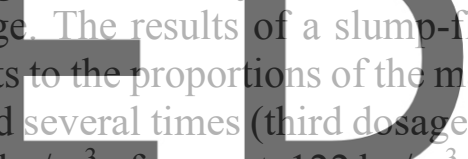
of water, $522 \mathrm{~kg} / \mathrm{m}^{3}$ of coarse RCA, $570 \mathrm{~kg} / \mathrm{m}^{3}$ of fine RCA, $343 \mathrm{~kg} / \mathrm{m}^{3}$ of siliceous sand 0/4

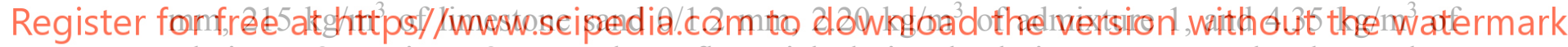
admixture 2. In Figure 3, some slump-flow trials during the design process can be observed.
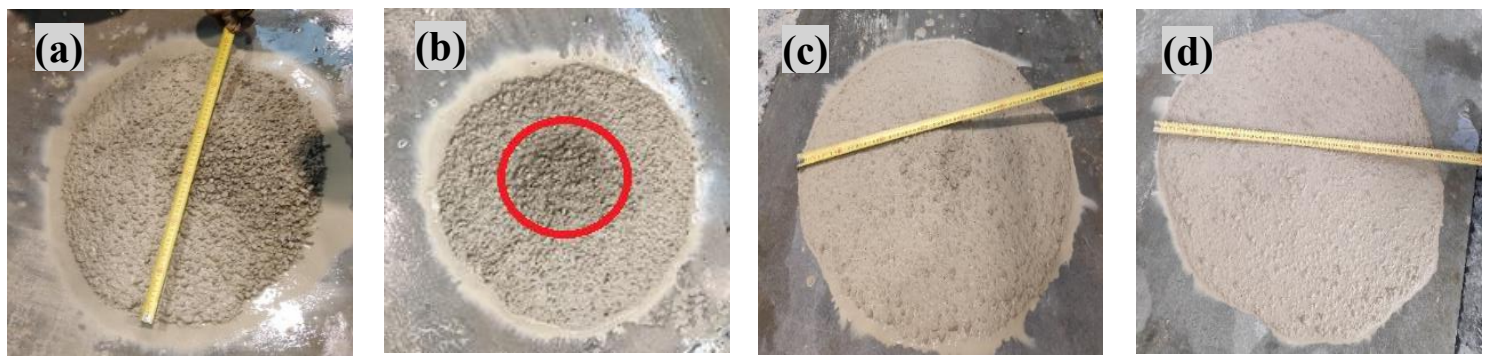

Figure 3. Dosages by trial and error during the development of the SCC: a) Initial dosage; b) Dosage with high segregation in the central area: c) Dosage with minimal segregation in the central area; d) Optimal dosage.

\section{In-Fresh State Behavior}

The slump flow test is insufficient in itself to ensure optimal SCC flowability and further characterization of the in-fresh state behavior is necessary (EFNARC, 2002).

- The slump flow test was performed first (EN 12350-8). A diameter of $500 \mathrm{~mm}$ was 
achieved in $4 \mathrm{~s}$, being the maximum diameter $720 \mathrm{~mm}$ (SF2 slump-flow class).

- Viscosity was measured by the time it took the SCC mix to pass through a V-funnel (EN 12350-9), which took 7s (viscosity class VF1, time under 8s).

- The 2-bar L-box test (EN 12350-10) measured the passing ability of the SCC. The quotient between the maximum and the minimum height was 0.97 (passing-ability class PA1, quotient greater than 0.80 and 2-bar L-box).

- The sieve segregation test (EN 12350-11) assessed the segregation resistance. The result obtained was $0.41 \%$ (SR2 class, segregation lower than $15 \%$ ).

\section{Compressive Strength}

Compressive strength at different ages was measured, to guarantee its structural suitability. Two specimens were tested at each age (1, 7 and 28 days),

At 1 day, the normalized sample already had a high compressive strength $(28 \mathrm{MPa}, 61.4 \%$ of 28-days strength). Increased strength over the first seven days was very fast $(84.0 \%$ of the final strength was reached at 28 days, $38.3 \mathrm{MPa}$ ). After three weeks, the compressive strength increase slowed down, reaching $45.6 \mathrm{MPa}$ at 28 days. The SCC could therefore be suitable for precast elements (compressive strength greater than $45 \mathrm{MPa}$ ).

\section{Durability}

Three durability tests were performed as part of the analysis of the effects of aggressive external agents: freeze/thaw and moist/dry test cycles, and sulphate attack. All the tests began on the
same day. $10 \mathrm{~cm}$-side cubic samples cured over 30 days were used. On first day of the tests
the compressive strength, measured on ty cubic samples, was $47.61 \mathrm{MPa}$ on average, which
subsequently became the referenee for any quantifiable decrease in compressive strength.
6.1 Freeze/Thaw Test

Register fErie Four $10 \mathrm{~cm}$-side cubic samples were introduced into a container full of water with $3 \%$ by mass of $\mathrm{NaCl}$ and subjected to 56 freeze/thaw cycles. In each 24h cycle, the container was exposed to $16 \mathrm{~h}$ of freezing at a temperature of $-15^{\circ} \mathrm{C}$ and to $8 \mathrm{~h}$ of thawing in water at $20^{\circ} \mathrm{C}$. Any loose materials were removed every 10 cycles and the specimens were then dried and weighed. Figure 4 shows the loss of mass and, Figure 5, the initial and final state of the test specimens.

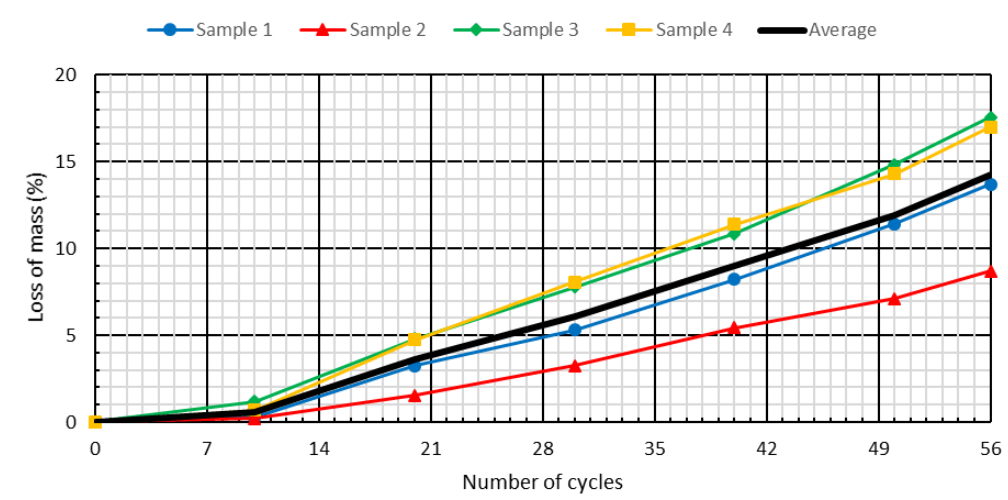

Figure 4. Loss of mass over freeze/thaw test. Average loss of mass at the end of the test: $14.23 \%$. 

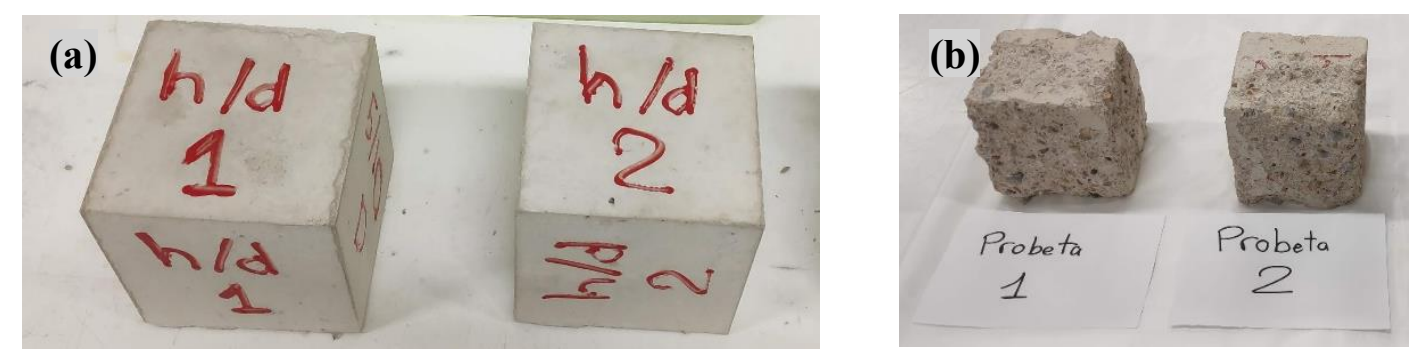

Figure 5. Freeze/thaw test: A) Initial state; B) Final state.

In addition to loss of mass, Ultrasonic Pulse Velocity (UPV), an indirect measure of compressive strength, was evaluated both before and after the test. The strength was also measured after the test. All the results are shown in Table 1.

Table 1. Freeze/thaw test. Results related to UPV and compressive strength

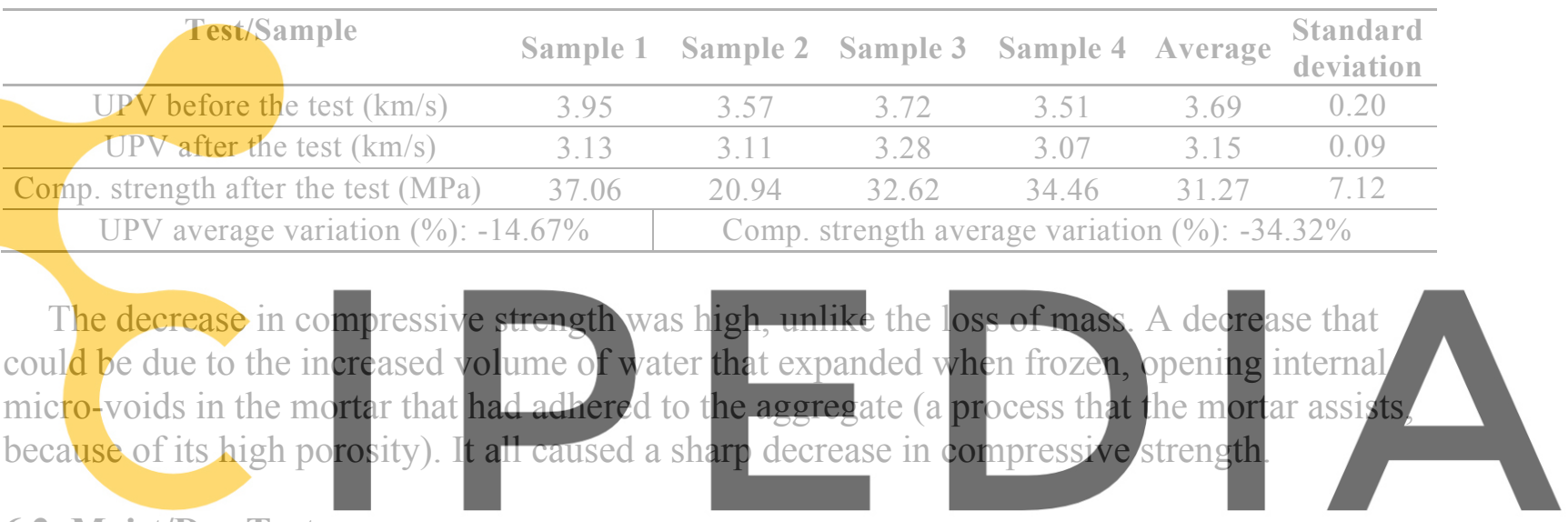

\subsection{Moist/Dry Test}

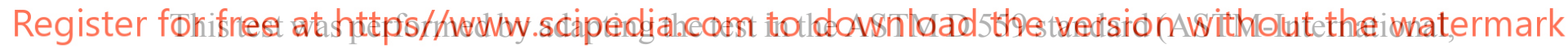
2008) that simulates the effects of rain and subsequent drying by solar radiation on concrete. Fundamentally, the thermal shock inflicted during the changeover from a wet to a dry situation. To do so, three $10 \mathrm{~cm}$-side cubic specimens were subjected to 30 24-hour cycles, which consisted of full immersion in water at a temperature between $18^{\circ} \mathrm{C}$ and $22^{\circ} \mathrm{C}$, over $16 \mathrm{~h}$, followed by oven drying for $8 \mathrm{~h}$ at $60^{\circ} \mathrm{C}$.

The external appearance of each sample after the test is shown in Figure 6. Every 10 cycles, each specimen was weighed and its UPV was measured, a parameter that had also been measured before the beginning of the test. When the trial ended, the samples were tested to compressive strength. The results obtained can be seen in Table 2.

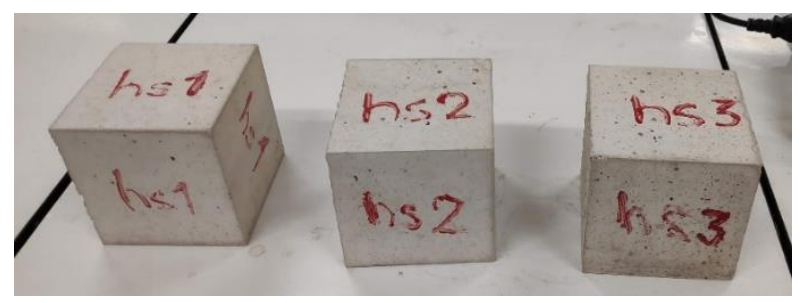

Figure 6. Moist/dry test. Final state of the samples. 
Table 2. Results of moist/dry test.

\begin{tabular}{|c|c|c|c|c|c|}
\hline Test/Sample & Sample 1 & Sample 2 & Sample 3 & Average & $\begin{array}{l}\text { Standard } \\
\text { deviation }\end{array}$ \\
\hline Initial mass $(\mathrm{g})$ & $2,068.8$ & $2,189.1$ & $2,094.1$ & $2,117.33$ & 63.42 \\
\hline Mass after 10 cycles $(\mathrm{g})$ & $2,043.5$ & $2,152.0$ & $2,047.1$ & $2,080.87$ & 61.63 \\
\hline Mass after 20 cycles $(\mathrm{g})$ & $2,022.2$ & $2,146.3$ & $2,044.8$ & $2,071.10$ & 66.10 \\
\hline Mass after the test, 30 cycles $(\mathrm{g})$ & 2015.8 & $2,140.0$ & $2,043.9$ & $2,066.57$ & 65.13 \\
\hline UPV before the test $(\mathrm{km} / \mathrm{s})$ & 3.72 & 3.79 & 3.64 & 3.71 & 0.08 \\
\hline UPV after the test $(\mathrm{km} / \mathrm{s})$ & 2.60 & 2.65 & 2.56 & 2.60 & 0.04 \\
\hline Comp. strength after the test (MPa) & 35.00 & 32.92 & 32.17 & 33.36 & 1.47 \\
\hline Mass average variation (\%): -2 & & \multicolumn{4}{|c|}{ UPV average variation (\%): $-29.87 \%$} \\
\hline
\end{tabular}

The external appearance (without appreciable changes except the increased number of external voids on sample $\mathrm{N}^{\mathrm{a}} 3$ ) and the loss of mass showed no visible change in the concrete. However, the compressive strength and the UPV showed significant changes at a microscopic level. Both changes could be explained by the appearance of larger internal micro voids than in the freeze/thaw test. Nevertheless, the decrease in compressive strength was very similar in both the moist/dry test and the freeze/thaw test. It appears that the large number of micro voids in the moist/dry test was compensated by the negligible loss of mass.
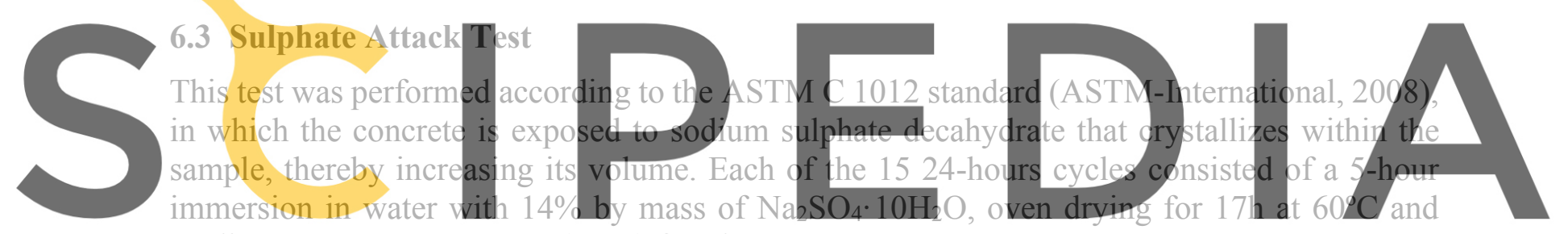
cooling at room temperature $\left(23^{\circ} \mathrm{C}\right)$ for $2 \mathrm{~h}$.

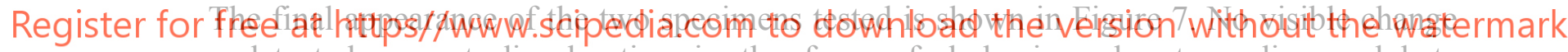
was detected, except discoloration in the form of darkening, due to sodium sulphate precipitation. Before and after the trial the samples were weighed, the length of their sides was measured (in order to determine the expansion of concrete by the absorption and crystallization of the salt) and the UPV was determined. In addition, both specimens were tested to compressive strength. All the results are indicated in Table 3.

Table 3. Sulphate attack test. Individual and average results.

\begin{tabular}{ccccc}
\hline Test/Sample & Sample 1 & Sample 2 & Average & Standard deviation \\
\hline Initial mass $(\mathrm{g})$ & $2,098.8$ & $2,199.2$ & $2,149.0$ & 70.99 \\
\hline Final mass $(\mathrm{g})$ & $2,083.9$ & $2,193.3$ & $2,138.6$ & 77.36 \\
\hline Initial average side length $(\mathrm{mm})$. & 100.11 & 100.33 & 100.22 & 0.16 \\
\hline Final average side length $(\mathrm{mm})$. & 100.13 & 100.34 & 100.24 & 0.15 \\
\hline UPV before the test $(\mathrm{km} / \mathrm{s})$ & 3.69 & 3.58 & 3.64 & 0.08 \\
\hline UPV after the test $(\mathrm{km} / \mathrm{s})$ & 3.38 & 2.63 & 3.01 & 0.53 \\
\hline Compressive strength after the test $(\mathrm{MPa})$ & 41.44 & 35.68 & 38.56 & 4.07 \\
\hline Mass average variation $(\%):-0.48 \%$ & \multicolumn{5}{c}{ Side expansion $(\%):+0.02 \%$} \\
\hline UPV average variation $(\%):-16.62 \%$ & Comp. strength average variation $(\%):-19.01 \%$ \\
\hline
\end{tabular}




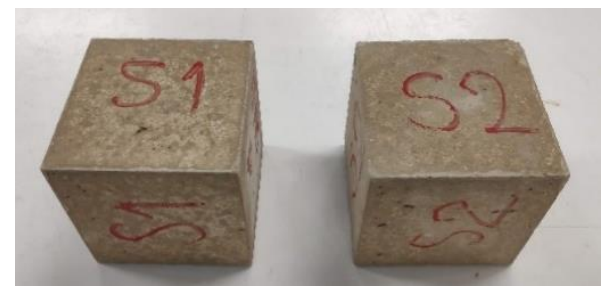

Figure 7. Sulphate attack test. Final state of the samples.

Neither the variation in either mass or length nor in the external appearance of the concrete samples showed relevant changes. The only noticeable effect was the reduction in compressive strength and the logical decrease in UPV. Nevertheless, compressive strength was less effected by the sulphates than by consequences of exposure to water in the moist/dry test. This difference can be explained by the high flowability of SCC, which implies that the concrete had a very low number of small-sized surface pores in the hardened state. Hence, the penetration of higher density solutions within the concrete was less likely, because water with no salt solutions penetrates with greater ease through surface pores than a sulphate solution, meaning that the sulphate effect would be lower towards the interior of the sample.

\section{Conclusions}

The following conclusions can be drawn from the study reported in this paper:
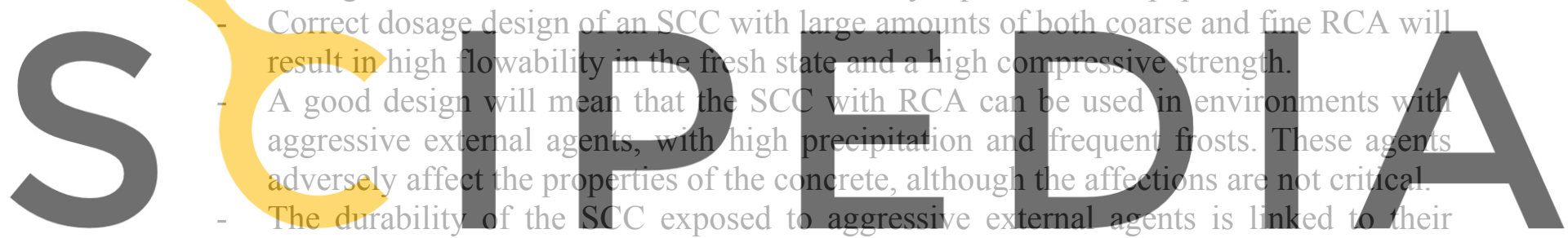
external porosity. In other words, the greater the ease with which the external agent

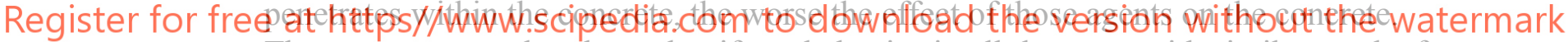

The concrete samples showed uniform behavior in all the tests, with similar results for all specimens, although those test results can vary depending on the surface finish. The homogeneity and workability of the mix was optimal when the specimens were manufactured, clearly demonstrating the uniform behavior and the durability of this SCC concrete for use in structural elements. This conclusion is based on the results obtained on four specimens in the freeze/thaw test, on three samples in the moist/dry test and two specimens in the sulphate attack test.

\section{Acknowledgments}

The authors want to express their gratitude to: the Vice Rectorate of Research of the University of Burgos (SUCONS grant); the Junta de Castilla y León for assistance to research group UIC-231 through project BU119P17 partially funded by FEDER funds; the Spanish Ministry MICIU and FEDER (European Regional Development Funds) for project funding FPU17/03374. 


\section{ORCID}

Víctor Revilla-Cuesta: http://orcid.org/0000-0003-3337-6250

Marta Skaf: http://orcid.org/0000-0001-7205-2692

Aratz García-Llona: http://orcid.org/0000-0002-8202-1424

Ignacio Piñero: http://orcid.org/0000-0003-1987-1677

Juan M. Manso: http://orcid.org/0000-0003-4964-5128

Vanesa Ortega-López: http://orcid.org/0000-0003-0212-355x

\section{References}

ANEFA (2018). Informe de situación económica sectorial.

ASTM-International (2008). Book Annual of ASTM Standars, West Conshohocken, 19429-2959 2008 USA PA.

Boudali, S., Kerdal, D.E., Ayed, K., Abdulsalam, B. and Soliman, A.M. (2016). Performance of self-compacting concrete incorporating recycled concrete fines and aggregate exposed to sulphate attack. Construction and Building Materials, 124, 705-713. doi: 10.1016/j.conbuildmat.2016.06.058.

Busic, R., Milicevic, I., Sipos, T.K. and Strukar, K. (2018). Recycled Rubber as an Aggregate Replacement in Self-Compacting Concrete-Literature Overview. Materials, 11(9). doi: 10.3390/ma11091729.

CEN Comité Europeo de Normalización, Comité Européen de Normalisation.

CESCE (2018). Informe sectorial de la economía española: Materiales de construcción.

EFNARC (2002). Specification Guidelines for Self-compacting Concrete, European Federation of National Associations Representing Producers and Applicators of Specialist Building Products for Concrete.

EN-Euronorm. Rue de stassart, 36. Belgium-1050 Brussels, European Committee for Standardization.

Evangelista, L. and De Brito, J. (2014). Concrete with fine recycled aggregates: A review. European Journal of Environmental and Civil Engineering, 18(2), 129-172. doi: 10.1080/19648189.2013.851038.

Fiol, F., Thomas, C., Muñoz, C., Ortega-López, V. and Manso, J.M. (2018). The influence of recycled aggregates from precast elements Building Materials, 1

Grdic, Z.J., Toplicic-Curcic concrete prepared with 1133. doi: 10.1016/j.ccont Guo, H., Shi, C., Guan, X aggregate concrete
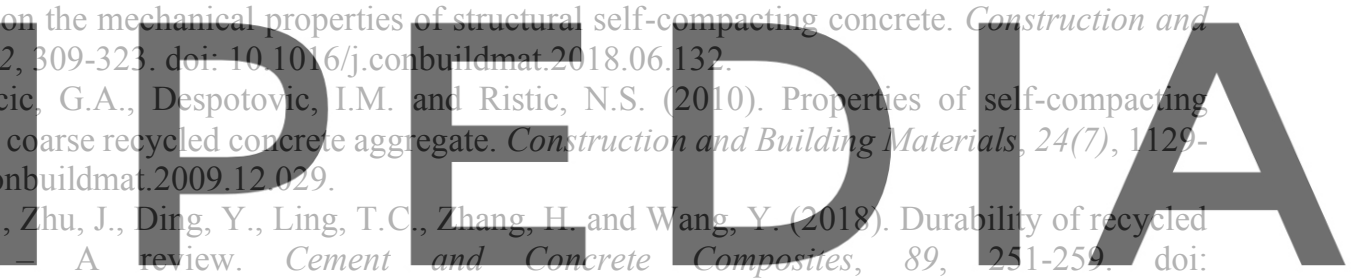
10.1016/j.cemconcomp.2018.03.008

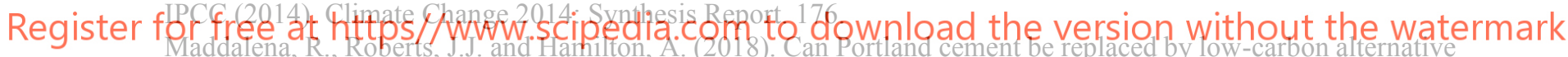
materials? A study on the thermal properties and carbon emissions of innovative cements. Journal of Cleaner Production, 186, 933-942. doi: 10.1016/j.jclepro.2018.02.138.

Noh, S., Son, Y. and Park, J. (2018). Life cycle carbon dioxide emissions for fill dams. Journal of Cleaner Production, 201, 820-829. doi: 10.1016/j.jclepro.2018.08.099.

Pereira-De-Oliveira, L.A., Nepomuceno, M.C.S., Castro-Gomes, J.P. and Vila, M.F.C. (2014). Permeability properties of self-Compacting concrete with coarse recycled aggregates. Construction and Building Materials, 51,113-120. doi: 10.1016/j.conbuildmat.2013.10.061.

Safiuddin, M., Alengaram, U.J., Rahman, M.M., Salam, M.A. and Jumaat, M.Z. (2013). Use of recycled concrete aggregate in concrete: A review. Journal of Civil Engineering and Management, 19(6), 796-810. doi: 10.3846/13923730.2013.799093.

Sandanayake, M., Zhang, G. and Setunge, S. (2019). Estimation of environmental emissions and impacts of building construction - A decision making tool for contractors. Journal of Building Engineering, 21, 173-185. doi: 10.1016/j.jobe.2018.10.023.

Silva, R.V., De Brito, J. and Dhir, R.K. (2015). The influence of the use of recycled aggregates on the compressive strength of concrete: A review. European Journal of Environmental and Civil Engineering, 19(7), 825-849. doi: 10.1080/19648189.2014.974831.

UNE-CEN/TS-12390-9-EX (2008). Testing hardened concrete. Part 9: Freeze-thaw resistance. Scaling.

Verian, K.P., Ashraf, W. and Cao, Y. (2018). Properties of recycled concrete aggregate and their influence in new concrete production. Resources, Conservation and Recycling, 133, 30-49. doi: 10.1016/j.resconrec.2018.02.005. 